\title{
DERIVA SIMULADA DE TRICLOPYR E FLUROXYPYR + TRICLOPYR NO DESENVOLVIMENTO DE MUDAS DE CLONES DE Eucalyptus
}

Gislean Pereira Carvalho², André Amaral da Silva ${ }^{3}$, Thomas Vieira Nunes², Fernando Araújo Barbosa ${ }^{4}$, José Iran Cardoso da Silva ${ }^{5}$, Fernando Barnabé Cerqueira ${ }^{6}$, Eduardo Andrea Lemus Erasmo ${ }^{5}$ e Renato Almeida Sarmento ${ }^{5}$

\begin{abstract}
RESUMO - O Estado do Tocantins tem-se destacado nos últimos anos como promissor em reflorestamentos com eucalyptus. Um dos problemas com grande destaque na silvicultura tocantinense é o amplo número de espécies infestantes (conhecidas comumente como rebrotas de Cerrado), resultantes de áreas recém-desmatadas. Objetivou-se com este trabalho avaliar o efeito da deriva simulada do herbicida triclopir e da mistura formulada triclopir + fluroxipir em mudas de clones de eucalipto, ambos em duas doses, correspondentes a 50 e $25 \%$ da dose de $7 \mathrm{~L} \mathrm{ha}^{-1}$ p.c, recomendados tradicionalmente em pastagem. Foram avaliadas as variações em altura de plantas, variações de diâmetro do caule, relação altura/diâmetro, acúmulo de massa de matéria seca: de folhas, de caules, de ramos, de raízes e total. Os herbicidas afetaram negativamente o crescimento dos clones de eucalipto até os 28 dias após a aplicação. Com base nos resultados, pode-se concluir que o efeito da deriva é menor quando os herbicidas triclopir e fluroxipir + triclopir são aplicados, ambos na dose de 25\%, diminuindo, assim, o risco de perdas.
\end{abstract}

Palavras-chave: Herbicidas; Controle químico; Reflorestamento.

\section{SIMULATED DRIFT OF TRICLOPYR AND FLUROXYPYR + TRICLOPYR ON DEVELOPMENT EUCalyptus CLONES}

\begin{abstract}
Recently, Tocantins State, Brazil, has been noticed in the field of reforestation by using eucalyptus species. One of the main problems of forestry in this State is the wide range of weed species (commonly known as regrowth of savanna), resulting from newly deforested areas. Thus, the aim of this study was to evaluate the effect of simulated drift auxin of two herbicides on growth of seedlings of eucalyptus clones. We used the herbicide fluroxypyr + triclopyr and triclopyr at two doses, corresponding to 50 and 25\% of the dose of $7 \mathrm{~L} \mathrm{ha^{-1 }} \mathrm{pc}$, traditionally recommended for pasture. We evaluated the variation in plant height, stem diameter increment, height / diameter ratio, dry matter accumulation on leaves, stems, branches, roots and total. The herbicides studied negatively affected the growth of eucalyptus clones untill the $28^{\text {th }}$ day after the application. Based on the results obtained, we conclude that the derived effect was lower when the herbicides triclopyr and fluroxypyr + triclopyr were applied, both at the dose of 25\%, thus decreasing the risk of yield losses at this dose.
\end{abstract}

Keywords: Herbicides; Chemical control; Reforestation.

\footnotetext{
${ }^{1}$ Recebido em 01.06.2013 aceito para publicação em 03.12.2013.

${ }^{2}$ Programa de Pós-graduação em Produção Vegetal, Universidade Federal do Tocantins, UFT/TO, Brasil. E-mail: <gisleancarvalho@hotmail.com>e <nunestv@uft.edu.br>.

${ }^{3}$ Departamento de Agronomia, Universidade Federal do Tocantins, UFT/TO, Brasil. E-mail: <andre.amaral.uft@hotmail.com>.

${ }^{4}$ Departamento de Engenharia Florestal, Universidade Federal do Tocantins, UFT/TO, Brasil. E-mail: <fernandoaraujob@hotmail.com>.

${ }^{5}$ Fundação Universidade Federal do Tocantins, Campus Universitário de Gurupi, UFT, Brasil. E-mail: <joseiranc@hotmail.com>; E-mail:<erasmolemus@uft.edu.br>e <rsarmento@uft.edu.br>.

${ }^{6}$ Programa de Pós-graduação em Biodiversidade e Biotecnologia, BIONORTE/ AM. E-mail: <fernando1.981@hotmail.com>.
} 


\section{INTRODUÇÃO}

Conforme a Associação Brasileira de Produtores de Florestas Plantadas - ABRAF (2013), no ano 2012 a área reflorestada com o gênero Eucalyptus no Brasil foi superior a cinco milhões de ha, sendo a área total de 109.00 ha no Estado do Tocantins, representando um aumento de 66,4\% em relação ao ano 2011.

O eucalipto é a essência florestal mais utilizada em programas de reflorestamento no Brasil, em razão de suas características de rápido crescimento, boa adaptação às condições edafoclimáticas existente no país e à multiplicidade de uso industrial (ABRAF, 2013).

Apesar de o gênero Eucalyptus apresentar espécies de rápido crescimento e de boa competitividade quanto ao seu estabelecimento no campo, isso não o isenta da interferência das plantas daninhas, que pode prejudicar o crescimento e desenvolvimento das plantas devido à competição por água, nutrientes e luz, principalmente no período inicial de desenvolvimento da cultura, tendo como consequência o decréscimo quantitativo e qualitativo da sua produção (AGOSTINETTO et al., 2010; MACHADO et al., 2010).

Entre as possibilidades de manejo de plantas daninhas, o método químico é o mais utilizado. Devido à escassez de produtos registrados à cultura do eucalipto para controle seletivo em pós-emergência das plantas daninhas, o uso do controle químico deve ser muito cauteloso, evitando causar injúrias e perdas de produtividade em função da deriva (TIBURCIO et al., 2012).

O éster butoxietílico do ácido 3,5,6-tricloro-2piridiloxiacético (triclopir) concerne ao grupo químico das piridinas, que é um herbicida sistêmico com absorção foliar e radicular, utilizado para o controle de plantas daninhas latifoliadas em pastagens e na cultura do arroz. Precisa de $4 \mathrm{~h}$ para ser absorvido pelas folhas, tendo translocação por toda a planta (NUNES, 2001).

A mistura formulada fluroxipir+triclopir é formada por dois ingredientes ativos, o 1-methylheptylester (4-amino-3,5-dichloro-6-fluoro-2-pyridyloxy) acetate (fluroxipir meptilíco) e butoxyethyl 3,5,6-trichloro-2pyridyloxyacetate (triclopir butotílico), herbicida sistêmico pertencente ao grupo químico do ácido piridiniloxialconoico, recomendado para o controle de plantas infestantes de folhas largas, semiarbustivas e arbustivas em áreas de pastagens (RODRIGUES; ALMEIDA, 2005).
Em áreas onde o controle químico é adotado, a deriva de herbicidas tem sido relatada com frequência, principalmente em aplicações dirigidas de produtos não seletivos, o que causa intoxicação, redução no crescimento e até a morte das plantas (TUFFI SANTOS et al., 2007). As principais causas de deriva são: tamanho da gota, altura da ponta de pulverização, velocidade de operação, velocidade do vento, temperatura, umidade do ar, volume de aplicação e formulação utilizada (FERREIRA et al., 2010).

Vários autores já demonstraram os prejuízos e os danos ocasionados pela deriva de herbicidas em eucalipto (SILVA et al., 1994; ADORYAN et al., 2002; TUFFI SANTOS et al., 2007; TAKAHASHI et al., 2009; AGOSTINETTO et al., 2010; TIBURCIO et al., 2012). Portanto, conhecer os efeitos da deposição de gotas indesejadas de herbicidas sobre plantas de eucalipto é fundamental para adoção desses produtos como alternativas viáveis no controle de plantas daninhas em reflorestamentos.

Considerando que a deriva de herbicidas pode prejudicar o desenvolvimento do eucalipto, o estudo de seus efeitos tem sido essencial para o uso de herbicidas não recomendados para essa cultura. Diante do exposto, objetivou-se com este trabalho avaliar o efeito da deriva simulada do herbicida triclopir e da mistura formulada triclopir + fluroxipir em mudas de clones de eucalipto.

\section{MATERIAL E MÉTODOS}

O estudo foi conduzido em vasos de plásticos com volume de $7 \mathrm{~L}$, em condições de campo na região Sul do Estado do Tocantins a $11^{\circ} 43^{\prime}$ S e $49^{\circ} 04^{\prime} \mathrm{W}$, a 280 m de altitude. O clima local, segundo a classificação de Köppen, é Tropical de savana (Aw) e úmido com pequena deficiência de água no inverno, megatérmico, com concentração da evapotranspiração no verão inferior a 48\% do total anual (B1wA'a'), segundo a classificação de Thornthwaite (PEEL, 2007).

O solo utilizado para enchimento dos vasos foi caracterizado como Latossolo Vermelho-Amarelo distrófico, textura média, sendo este um solo típico de Cerrado (EMBRAPA, 2006), cujos atributos químicos expressos em $\mathrm{cmol}_{\mathrm{c}} \mathrm{dm}^{-3}$ (exceto $\mathrm{pH}$ ) foram: $\mathrm{Ca}=4,3$, $\mathrm{Mg}=2,6, \mathrm{Al}=01, \mathrm{H}+\mathrm{Al}=3,3$ e $\mathrm{K}=0,6 ; \mathrm{pH}$ em $\mathrm{H}_{2} \mathrm{O}$ $=5,8$ e em $\mathrm{Cacl}_{2}=5,0$ e os atributos físicos: areia $=$ $76 \%$, silte $=6 \%$ e argila $=18 \%$. 
Mudas padronizadas dos clones GG-100 (híbrido de E. urophylla $\times$ grandis $^{1}$ ), GG-157 (híbrido de E. urophylla), VM-01 (híbrido de E. urophylla $x$ camaldulensis), VE-06 (híbrido de E. urophylla $x$ grandis $^{2}$ ) e HC (híbrido de E. urophylla $\times$ grandis $^{3}$ ), com aproximadamente $30 \mathrm{~cm}$ de altura e três meses de idade, foram transplantadas em vasos, os quais receberam adubação com $\mathrm{P}_{2} \mathrm{O}_{5}$ e ureia $\left(6\right.$ g vaso $\left.^{-1}\right)$. Aos 30 dias após o transplante, quando as plantas apresentavam cerca de $50 \mathrm{~cm}$ de altura, foram realizadas as aplicações em jato dirigido com pulverizador costal equipado com pontas bico (XR 110.02), com volume de calda de $200 \mathrm{~L} \mathrm{ha}^{-1}$ e pressão constante de 35 psi. A aplicação foi feita de modo a não atingir o terço superior da planta, portanto foram utilizados sacos plásticos protegendo o terço superior da copa.

Utilizou-se o delineamento inteiramente casualizado com quatro repetições em um esquema fatorial 5 x 2 x 2, correspondendo a cinco clones de Eucalyptus (híbrido de E. urophylla $\times$ grandis ${ }^{1}$, híbrido de E. urophylla, híbrido de E. urophylla x camaldulensis, híbrido de E. urophylla $\times$ grandis ${ }^{2}$ e híbrido de E. urophylla $\times$ grandis $^{3}$ ), dois herbicidas (fluroxipir e triclopir + fluroxipir) e duas doses (25 e 50\% da dose recomendada tradicionalmente em pastagens para cada produto) (Tabela 1).

Antes da aplicação, todas as plantas foram mensuradas quanto à sua altura (da superfície do solo até a folha mais alta, em cm) e diâmetro do caule (a $2 \mathrm{~cm}$ da superfície do solo, em mm). Essas mesmas medidas foram realizadas no final do experimento, de forma a se obterem as variações referentes ao período.

Após a aplicação dos herbicidas, foram observadas, periodicamente (aos 7, 14, 21 e 28 dias após a aplicação - DDA), alterações morfológicas na parte aérea das plantas, visíveis a olho nu, e avaliou-se a fitotoxicidade em relação à testemunha, por meio de escala de notas de 0 a $100 \%$, em que $0 \%$ para ausência de sintomas e $100 \%$ para morte total da planta (FRANS, 1972).

Aos 50 DAA, a parte aérea e radicular das plantas foram colhidas, separadas e acondicionadas em sacos de papel, mantidas em estufa com circulação de ar (70 $\pm 2{ }^{\circ} \mathrm{C}$ ) até atingir peso constante. Posteriormente, avaliaram-se as variáveis: variação da altura de plantas $\left(H_{\mathrm{i}}\right)$; variação do diâmetro do caule $\left(\mathrm{D}_{\mathrm{i}}\right)$; relação altura/ diâmetro final (H/D); acúmulo de massa de matéria seca das folhas (MMSF), do caule (MMSC), dos ramos $\left(M_{M S R}\right.$ am), das raízes (MMSR) e massa de matéria seca total (MMST).

Os dados foram submetidos à análise de variância pelo teste $\mathrm{f}$ e as médias de $\mathrm{H}_{\mathrm{i}}, \mathrm{D}_{\mathrm{i}}, \mathrm{H} / \mathrm{D}, \mathrm{MMSF}$, MMSC, MMSR $_{\mathrm{am}}$, MMSR e MST, comparadas pelo teste de Tukey $(\mathrm{p}<0,05)$. Já as médias de fitotoxicidade foram transformadas em graus radianos: arcosseno $(\bigvee \mathrm{x} / 100)$ *180/ð e submetidas ao teste de Tukey $(\mathrm{p}<0,05)$.

\section{RESULTADOS}

Aos 7 DAA dos herbicidas foram observadas diferenças significativas no clone híbrido de E. urophylla (Tabela 2), com maiores notas de intoxicação para os tratamentos fluroxipir+triclopir ${ }^{(50 \%)}$ e triclopir ${ }^{(50 \%)}$. As notas visuais de toxicidade estiveram entre 21 e $41 \%$ para esse período.

Os sintomas de intoxicação observados a partir dos 7 DAA em plantas dos clones híbridos de E. urophylla e híbridos de E. urophylla $\times$ grandis $^{1}$ expostas à aplicação do tratamento triclopir ${ }^{(50 \%)}$ constaram do retorcimento dos tecidos tenros, ramos e folhas novas, seguido da morte dos ramos.

Tabela 1 - Tratamentos avaliados e as respectivas quantidades de ingrediente ativo, óleo mineral e produto comercial por hectare.

Table 1 - Treatments evaluated and their respective quantities of active ingredient, mineral oil and commercial product per hectare.

\begin{tabular}{|c|c|c|c|c|}
\hline \multicolumn{2}{|l|}{ Tratamentos } & \multirow{2}{*}{ Óleo (L/ha) } & \multirow{2}{*}{ Dose p.c (L/ha) } & \multirow{2}{*}{ \% dose recomendada } \\
\hline Herbicidas & Dose i.a (g ha $\left.{ }^{-1}\right)$ & & & \\
\hline Testemunha & - & - & & - \\
\hline Fluroxipir + triclopir & $140+420$ & 1 & 1,75 & 25 \\
\hline Fluroxipir + triclopir & $280+840$ & 1 & 3,50 & 50 \\
\hline Triclopir & 840 & 1 & 1,75 & 25 \\
\hline Triclopir & 1680 & 1 & 3,50 & 50 \\
\hline
\end{tabular}


Verificaram-se diferenças significativas entre clones no tratamento triclopir ${ }^{(25 \%)}$, com maiores notas de intoxicação dos clones híbridos de E. urophylla $x$ grandis $^{2}$ e híbridos de E. urophylla $x$ grandis $^{3}$ (37,5 e 27,93\%, respectivamente).

Ainda aos 7 DAA foi observado nas plantas do clone híbrido de $E$. urophylla $x$ grandis ${ }^{1}$ nos tratamentos fluroxipir+triclopir ${ }^{(50 \%)}$ e triclopir ${ }^{(50 \%)}$ sintomas típicos de intoxicação por herbicidas mimetizadores de auxinas, como alongamento do pecíolo e epinastia foliar. O mesmo sintoma foi observado nas plantas do clone híbrido de E. urophylla aos 14 DAA, no tratamento fluroxipir+triclopir ${ }^{(25 \%)}$.

Decorridos 14DAA, verificou-se que o clone híbrido de E. urophylla $\times$ grandis $^{1}$ foi o único a não apresentar diferença significativa entre os tratamentos. Ficou evidente o aumento da intoxicação com o tratamento triclopir ${ }^{(50 \%)}$ em todos os clones, sendo nesse tratamento verificadas as maiores notas de intoxicação, que variaram entre 35 e 48\%, esta última correspondente ao clone híbrido de $E$. urophylla x grandis ${ }^{3}$, que se diferenciou significativamente dos outros clones.

$\mathrm{Na}$ avaliação ocorrida aos 21 DAA, diferenças significativas entre tratamentos foram constatadas para os clones híbridos de E. urophylla x grandis ${ }^{1}$, híbridos de E. urophylla e híbridos de E. urophylla x grandis $^{3}$. Diferenças estatísticas também foram verificadas nos tratamentos fluroxipir+triclopir ${ }^{(50 \%)}$ e triclopir ${ }^{(50 \%)}$, com maiores notas de fitotoxicidade observadas no clone híbrido de E. urophylla x grandis ${ }^{3}$.

Os clones híbridos de E. urophylla e híbridos de E. urophylla $x$ grandis $^{1}$ no tratamento fluroxipir+triclopir ${ }^{(25 \%)}$, o clone híbrido de E. urophylla x camaldulensis no tratamento fluroxipir+triclopir ${ }^{(50 \%)}$ e o clone híbrido de E. urophylla $\times$ grandis $^{1}$ no tratamento triclopir ${ }^{(25 \%)}$ aos 21 DAA apresentaram a emissão desordenada de brotação ao longo do caule. Nesse mesmo período, plantas do clone híbrido de E. urophylla $\times$ grandis $^{3}$ expostas ao tratamento triclopir ${ }^{(25 \%)}$ apresentaram sintomas de clorose internerval.

Verificou-se que quase todos os tratamentos promoveram maiores variações na altura de plantas em relação à testemunha, com exceção do clone híbrido de E. urophylla, para o tratamento triclopir ${ }^{(25 \%)}$. No clone híbrido de E. urophylla $\times$ grandis ${ }^{2}$, foram observadas as maiores variações em altura de plantas (acima de 60\% quando comparado com a sua testemunha), em resposta ao efeito dos herbicidas aplicados.

Quanto ao incremento em diâmetro de caule em mudas de clones de eucalipto, não houve efeito significativo dos herbicidas nos clones e entre eles (Tabela 3).

Verificou-se, na massa de matéria seca de ramos, que o clone híbrido de E. urophylla $\times$ grandis ${ }^{1}$ apresentou diferença significativa nos tratamentos fluroxipir+triclopir ${ }^{(25 \%)}$, fluroxipir + triclopir ${ }^{(50 \%)}$ e triclopir (25\%) em relação aos demais clones (Tabela 4), apresentando as menores médias e uma redução na massa de 8,82\% em relação à testemunha.

O herbicida fluroxipir + triclopir ${ }^{(25 \%)}$ aumentou a massa seca de caule nas plantas do clone híbrido de E. urophylla $\times$ grandis $^{2}$, sendo verificado o mesmo comportamento do clone híbrido de E. urophylla $x$ camaldulensis, com aumento de 54,7\% no incremento quando comparado à testemunha.

Foi observado que não houve diferenças significativas para massa de matéria seca de folhas, mas foi possível notar tendência de aumento da MSF no clone híbrido de E. urophylla x camaldulensis em todos os tratamentos, comparados à testemunha.

Não foram observadas diferenças significativas dos tratamentos sobre a massa de raízes e a massa seca total.

\section{DISCUSSÃO}

Aos 7 DAA dos tratamentos, os clones híbrido de E. urophylla e híbrido de E. urophylla $\times$ grandis $^{1}$ apresentaram sintomas de intoxicação com as notas visuais de toxicidade entre 38 e $40 \%$ para o clone híbrido de E. urophylla e 21 e 30\% para o clone híbrido de E. urophylla $\times$ grandis $^{1}$ nos tratamentos com as maiores doses dos herbicidas. Esses sintomas caracterizaram-se como retorcimento dos tecidos tenros, epinastia foliar e alongamento dos pecíolos seguidos da morte dos ramos que estiveram em contato com a molécula do herbicida. Tuffi Santos et al. (2006) observaram os mesmos sintomas quando simularam a deriva de triclopir em Eucalyptus, caracterizados por retorcimento dos ápices e epinastia das folhas. De acordo com Ahrens (1994), os herbicidas auxínicos agem nas plantas de forma a reduzir o pH do apoplástico que induz a alongação celular pelo aumento da atividade enzimática responsável 
pelo afrouxamento celular. O incremento nesse processo leva à síntese de auxinas e giberelinas, as quais promoverão divisão e alongamento celular acelerado e desordenado nas partes novas da planta, ativando seu metabolismo e levando ao seu colapso.

Os clones híbrido de E. urophylla e híbrido de E. urophylla $\times$ grandis $^{1}$, quando submetido aos tratamentos, apresentaram aos 21 DAA a emissão desordenada de brotação ao longo do caule. Em trabalho semelhante, com deriva de glifosato em clones de eucalipto, Tuffi Santos et al. (2005) relataram a emissão de brotações anormais e sintomas de intoxicação em plantas expostas às subdoses do produto. Os herbicidas auxínicos são conhecidos por regular o fenômeno de dominância apical em plantas superiores, e a emissão de brotações anormais está em função do estímulo

Tabela 2 - Fitointoxicação (\%) em graus radiano em mudas de clones de eucalipto 7, 14, 21 e 28 dias após a aplicação dos herbicidas triclopir e fluroxipir+triclopir em duas doses, em Gurupi, TO, 2011.

Table 2 - Phytotoxicity (\%) in radian in seedlings of eucalyptus clones 7; 14; 21 and 28 days after application of the herbicides triclopyr and fluroxypyr + triclopyr at two doses. Gurupi - Tocantins State, Brazil, 2011.

\begin{tabular}{|c|c|c|c|c|c|c|c|c|}
\hline \multirow[t]{3}{*}{ Datas } & \multirow[t]{2}{*}{ Tratamentos } & \multicolumn{7}{|c|}{ Clones } \\
\hline & & \multicolumn{2}{|c|}{ E.urograndis ${ }^{1}$} & \multicolumn{2}{|c|}{ E. urophylla } & E. urograndis ${ }^{3}$ & E. urograndis $^{2}$ & E. urocan \\
\hline & Fluro+triclo ${ }^{(25 \%)}$ & 26,97 & Aa & 31,73 & Aab & 32,89 Аа & 31,23 Аа & 35,42 Аа \\
\hline & Fluro +triclo ${ }^{(50 \%)}$ & 30,77 & Aa & 38,37 & $\mathrm{Aa}$ & 31,53 Аа & 37,77 Аа & 33,71 Аа \\
\hline \multirow[t]{5}{*}{7 dias } & Triclopir ${ }^{(25 \%)}$ & 21,71 & $\mathrm{Ba}$ & 22,66 & $\mathrm{Bb}$ & $27,93 \mathrm{ABa}$ & 37,51 Аа & $23,75 \mathrm{Ba}$ \\
\hline & Triclopir ${ }^{(50 \%)}$ & 28,36 & Aa & 40,64 & $\mathrm{Aa}$ & 35,80 Аа & 31,91 Аа & 29,96 Аа \\
\hline & $\mathrm{F}$ & $1,46^{(\mathrm{ns})}$ & & $6,46 * *$ & & $1,06^{(\mathrm{ns})}$ & $1,22^{\text {(ns) }}$ & $2,65^{(\mathrm{ns})}$ \\
\hline & DMS & & & & & 11,95 & & \\
\hline & CV (\%) & & & & & 20,13 & & \\
\hline \multirow[t]{4}{*}{ Datas } & Tratamentos & & & & & Clones & & \\
\hline & & E.urogrand & & E. urophyl & & E. urograndis ${ }^{3}$ & E. urograndis ${ }^{2}$ & E. urocan \\
\hline & Fluro+triclo ${ }^{(25 \%)}$ & 25,55 & Аа & 23,37 & $\mathrm{Ab}$ & $26,35 \mathrm{Ab}$ & $26,58 \quad \mathrm{Ab}$ & $24,69 \mathrm{Ab}$ \\
\hline & Fluro + triclo ${ }^{(50 \%)}$ & 33,19 & Aa & 36,24 & Аа & $36,24 \mathrm{Ab}$ & 32,27 Aab & 31,47 Aab \\
\hline \multirow[t]{5}{*}{14 dias } & Triclopir ${ }^{(25 \%)}$ & 29,78 & Аа & 34,00 & Aab & $28,96 \mathrm{Ab}$ & 33,10 Aab & $27,21 \mathrm{Ab}$ \\
\hline & Triclopir ${ }^{(50 \%)}$ & 35,46 & $\mathrm{Ba}$ & 42,86 & Aba & 48,05 Аа & $37,65 \mathrm{ABa}$ & 40,66 Aba \\
\hline & $\mathrm{F}$ & $2,31^{(\mathrm{ns})}$ & & $8,19^{* *}$ & & $11,79 * *$ & $2,58^{*}$ & $3,93 *$ \\
\hline & DMS & & & & & 10,66 & & \\
\hline & CV (\%) & & & & & 17,41 & & \\
\hline \multirow[t]{4}{*}{ Datas } & Tratamentos & & & & & Clones & & \\
\hline & & E.urogrand & & E. urophyl & & E. urograndis ${ }^{3}$ & E. urograndis ${ }^{2}$ & E. urocan \\
\hline & Fluro+triclo ${ }^{(25 \%)}$ & 30,61 & Аа & 31,04 & Aab & 31,41 Aab & 23,37 Аа & 27,07 Аа \\
\hline & Fluro + triclo ${ }^{(50 \%)}$ & 30,77 & Aba & 33,93 & Aba & 39,91 Аа & $29,75 \quad \mathrm{ABa}$ & $25,64 \mathrm{Ba}$ \\
\hline \multirow[t]{5}{*}{21 dias } & Triclopir ${ }^{(25 \%)}$ & 15,69 & $\mathrm{Ab}$ & 21,57 & $\mathrm{Ab}$ & $20,48 \mathrm{Ab}$ & 24,46 Аа & 20,62 Аа \\
\hline & Triclopir $(50 \%)$ & 20,62 & Bab & 29,96 & $\mathrm{ABab}$ & 38,70 Аа & $22,66 \quad$ Ва & $25,55 \mathrm{Ba}$ \\
\hline & $\mathrm{F}$ & $5,95^{*}$ & & $2,79 *$ & & $7,90 * *$ & $1,02^{(\mathrm{ns})}$ & $0,78^{(\mathrm{ns})}$ \\
\hline & DMS & & & & & 11,95 & & \\
\hline & CV (\%) & & & & & 23,36 & & \\
\hline \multirow[t]{3}{*}{ Datas } & Tratamentos & & & & & Clones & & \\
\hline & & E.urogrand & & E. urophyl & & E. urograndis ${ }^{3}$ & E. urograndis ${ }^{2}$ & E. urocan \\
\hline & $\begin{array}{l}\text { Fluro+triclo }{ }^{(25 \%)} \\
\text { Fluro + triclo } \\
(50 \%)\end{array}$ & $\begin{array}{l}20,4 \varepsilon \\
25,26\end{array}$ & & $\begin{array}{l}24,3 \\
27,4\end{array}$ & & $\begin{array}{l}21,57 \\
19,57\end{array}$ & $\begin{array}{l}19,53 \\
20,62\end{array}$ & $\begin{array}{l}23,00 \\
26,91\end{array}$ \\
\hline \multirow[t]{5}{*}{28 dias } & Triclopir ${ }^{(25 \%)}$ & 19,53 & & 18,4 & & 20,63 & 19,23 & 18,44 \\
\hline & Triclopir (50\%) & $20,4 \varepsilon$ & & 22,6 & & 31,73 & 23,23 & 24,32 \\
\hline & $\mathrm{F}$ & $0,45^{\text {(n }}$ & & $0,95^{(\mathrm{n}}$ & & $2,15^{(\mathrm{ns})}$ & $0,20^{\text {(ns) }}$ & $0,86^{(\mathrm{ns})}$ \\
\hline & DMS & & & & & 14,45 & & \\
\hline & CV (\%) & & & & & 34,23 & & \\
\hline
\end{tabular}

Médias seguidas da mesma letra minúscula nas colunas e maiúsculas nas linhas não diferem estatisticamente pelo teste de Tukey ( $\leq \leq 0,05)$; $(*)$ e $(* *)$ significativo a $\left(\mathrm{pd}^{*} 0,05\right)$ e $(\mathrm{p}<0,01)$, respectivamente; $\left({ }^{\mathrm{ns}}\right)$ não significativo: fluro+triclo ${ }^{(25 \%)}$; tratamento fluroxipir+triclopir a $25 \%$ da dose recomendada; fluro+triclo ${ }^{(50 \%)}$ : tratamento fluroxipir+triclopir a $50 \%$ da dose recomendada. E. urograndis ${ }^{1}=$ clone GG-100 (híbrido de E. urophylla x grandis); E. urophylla = clone GG-157 (híbrido de E. urophylla); E. urograndis² = clone VE-06 (híbrido de E. urophylla $\times$ grandis); E. urograndis ${ }^{3}=$ clone HC (híbrido de E. urophylla $\times$ grandis); e E. urocan = clone VM-01 (híbrido de E. urophylla $x$ camaldulensis).

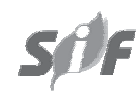

Revista Árvore, Viçosa-MG, v.38, n.1, p.165-173, 2014 
à produção e liberação de citocininas que têm sido implicadas na liberação de gemas axilares da dominância apical (TAMAS, 1995; TAIZ; ZEIGER, 1998).

Nesse mesmo período, folhas de plantas do clone híbrido de E. urophylla $\times$ grandis ${ }^{3}$ submetidas ao tratamento triclopir ${ }^{(25 \%)}$ apresentaram sintomas de clorose interneval, seguida de necrose. Os primeiros efeitos nas plantas dicotiledôneas sensíveis são aos herbicidas hormonais, caracterizados por anormalidades no crescimento, como epinastia e inibição do crescimento com intensificação da pigmentação verde foliar dentro de 24 h. Esses fenômenos são seguidos por dano nos cloroplastos, causando clorose e destruição da integridade das membranas e do sistema vascular, culminando em dessecação e necrose dos tecidos (GROSSMANN, 2000).

Aos 28 DAA foi evidente o decréscimo das notas de fitotoxicidade para todos os tratamentos em todos os clones, não sendo observadas diferenças significativas entre estes. Conforme Ferreira et al. (2005), algumas espécies de plantas podem excretar os herbicidas hormonais para o solo através de seu sistema radicular, e o estádio de desenvolvimento da planta, no momento da aplicação do herbicida, pode garantir a seletividade de algumas auxinas sintéticas. Avaliando o efeito da deriva de triclopir em Eucalyptus, Tuffi Santos et al. (2006) observaram que a intoxicação das plantas variou de acordo com as subdoses, sendo tanto maior quanto maiores as subdoses, havendo recuperação das plantas aos 45 DAA. Esses mesmos autores observaram que, quando comparados com a deriva de glyphosate, carfentrazone-ethyl e triclopir, a menos danosa às plantas de eucalipto foi a do triclopir.

Quanto à altura de plantas, quase todos os tratamentos promoveram, nos clones testados, variações superiores à testemunha. Conforme Grossmann e Hansen (2001), baixas concentrações de auxinas podem reduzir a formação de etileno e promover o crescimento por alongamento e divisão celular.

Tabela 3 - Variação da altura de planta e variação de diâmetro do caule de mudas de clones de eucalipto 50 dias após a aplicação dos herbicidas triclopir e fluroxipir + triclopir em duas doses Gurupi, TO, 2011.

Table 3 - Plant height and stem diameter of seedlings of eucalyptus clones 50 days after application of herbicides triclopyr and fluroxypyr + triclopyr at two doses Gurupi, Tocantins State, Brazil, 2011.

\begin{tabular}{|c|c|c|c|c|c|c|c|c|}
\hline \multicolumn{2}{|c|}{ Tratamentos } & \multicolumn{7}{|c|}{$\begin{array}{l}\text { Variação (\%) } \\
\text { Clones }\end{array}$} \\
\hline \multirow{9}{*}{$\begin{array}{l}\text { Altura } \\
(\mathrm{cm})\end{array}$} & & E.urogran & & E. urophy & & E. urograndis 3 & E. urograndis ${ }^{2}$ & E. urocan \\
\hline & Fluro+triclo ${ }^{(25 \%)}$ & 71,65 & Аа & 56,57 & $\mathrm{Ab}$ & 59,64 Аа & 61,97 Аа & 43,97 Аа \\
\hline & Fluro + triclo ${ }^{(50 \%)}$ & 50,17 & Aa & 55,32 & Aab & 56,96 Аа & 65,01 Аа & 40,44 Аа \\
\hline & Triclopir $^{(25 \%)}$ & 55,21 & Aa & 29,76 & $\mathrm{Bc}$ & $46,55 \mathrm{ABa}$ & 63,21 Аа & 39,55 Aba \\
\hline & Triclopir ${ }^{(50 \%)}$ & 51,72 & Aa & 60,57 & Aa & 47,76 Аа & 67,14 Аа & 57,28 Аа \\
\hline & Testemunha & 44,79 & & 31,58 & Abc & 44,60 Аа & 43,58 Аа & 33,27 Аа \\
\hline & $\mathrm{F}$ & 1,7 & & & & $1,04^{(\mathrm{ns})}$ & $1,5^{(\mathrm{ns})}$ & $1,53^{\text {(ns) }}$ \\
\hline & DMS & & & & & 26,70 & & \\
\hline & $\mathrm{CV}(\%)$ & & & & & 14,86 & & \\
\hline \multicolumn{2}{|c|}{ Tratamentos } & \multicolumn{7}{|c|}{$\begin{array}{c}\text { Variação (\%) } \\
\text { Clones }\end{array}$} \\
\hline \multirow{9}{*}{$\begin{array}{l}\text { Diâmetro } \\
(\mathrm{mm})\end{array}$} & & \multicolumn{2}{|c|}{ E.urograndis ${ }^{1}$} & \multicolumn{2}{|c|}{ E. urophylla } & E. urograndis 3 & E. urograndis ${ }^{2}$ & E. urocan \\
\hline & Fluro+triclo ${ }^{(25 \%)}$ & \multicolumn{2}{|c|}{44,92} & \multirow{2}{*}{\multicolumn{2}{|c|}{$\begin{array}{l}30,76 \\
33,06\end{array}$}} & 55,12 & \multirow{2}{*}{$\begin{array}{l}54,38 \\
54,62\end{array}$} & 43,72 \\
\hline & Fluro + triclo ${ }^{(50 \%)}$ & \multicolumn{2}{|c|}{33,73} & & & 43,72 & & 38,57 \\
\hline & Triclopir ${ }^{(25 \%)}$ & \multirow{2}{*}{\multicolumn{2}{|c|}{$\begin{array}{l}45,21 \\
37,14\end{array}$}} & \multicolumn{2}{|c|}{37,94} & 41,76 & $\begin{array}{l}54,02 \\
38,39\end{array}$ & 41,34 \\
\hline & Triclopir ${ }^{(50 \%)}$ & & & \multicolumn{2}{|c|}{33,24} & 40,34 & 34,60 & 31,19 \\
\hline & Testemunha & \multicolumn{2}{|c|}{34,75} & \multicolumn{2}{|c|}{35,49} & 49,83 & \multirow{2}{*}{$\begin{array}{l}46,07 \\
1,8^{\text {(ns) }}\end{array}$} & 43,39 \\
\hline & $\mathrm{F}$ & \multicolumn{2}{|c|}{$0,75^{(\mathrm{ns})}$} & \multirow{2}{*}{\multicolumn{2}{|c|}{$0,13^{*}$}} & $0,82^{(\mathrm{ns})}$ & & $0,92^{(\mathrm{ns})}$ \\
\hline & DMS & & & & & 10,58 & & \\
\hline & $\mathrm{CV}(\%)$ & & & & & 15,6 & & \\
\hline
\end{tabular}

Médias seguidas da mesma letra minúscula nas colunas e maiúsculas nas linhas não diferem estatisticamente pelo teste de Tukey (p $\leq 0,05$ ); $\left.{ }^{*}\right)$ significativo a (pd”0,05) e ( ${ }^{\text {ns }}$ ) não significativo; fluro+triclo ${ }^{(25 \%)}$ : tratamento fluroxipir+triclopir a 25\% da dose recomendada; fluro+triclo ${ }^{(50 \%)}$. tratamento fluroxipir+triclopir a 50\% da dose recomendada. E. urograndis ${ }^{1}=$ clone GG-100 (híbrido de E. urophylla $x$ grandis); E. urophylla

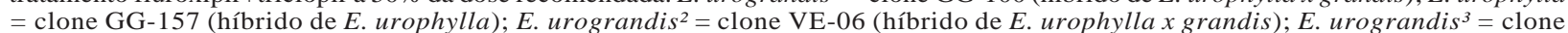
HC (híbrido de E. urophylla x grandis); e E. urocan = clone VM-01 (híbrido de E. urophylla x camaldulensis).

Revista Árvore, Viçosa-MG, v.38, n.1, p.165-173, 2014 
Deriva simulada de Triclopyr e Fluroxypyr + Triclopyr no...

Tabela 4 - Massa seca de ramos (MSR), de folha (MSF), de caule (MSC) e massa seca total (MST) de clones de eucalipto 50 dias após a aplicação dos herbicidas triclopir e fluroxipir+triclopir Gurupi, TO, 2011.

Table 4 - Dry mass of branches (MSR), leaf (MSF), stem (MSC) and total dry matter (TDM) of eucalyptus clones 50 days after application of herbicides triclopyr and fluroxypyr + triclopyr Gurupi, TO, 2011.

\begin{tabular}{|c|c|c|c|c|c|c|}
\hline & Tratamentos & & & Clones & & \\
\hline & & E.urograndis ${ }^{1}$ & E. urophylla & E. urograndis ${ }^{3}$ & E. urograndis ${ }^{2}$ & E. urocan \\
\hline & Fluro+triclo ${ }^{(25 \%)}$ & $7,25 \quad \mathrm{Ba}$ & $10,93 \mathrm{ABa}$ & $12,10 \mathrm{Aa}$ & 9,98 $\mathrm{ABa}$ & $12,25 \mathrm{Aa}$ \\
\hline & Fluro +triclo ${ }^{(50 \%)}$ & $7,25 \quad \mathrm{Ba}$ & $10,50 \mathrm{ABa}$ & $12,05 \mathrm{Aa}$ & $8,65 \mathrm{ABa}$ & 9,25 Aba \\
\hline MS(g) & Triclopir (25\%) & $7,75 \quad \mathrm{Ba}$ & $10,75 \mathrm{ABa}$ & $12,25 \mathrm{Aa}$ & $10,38 \mathrm{ABa}$ & 9,00 Aba \\
\hline \multirow[t]{9}{*}{ Ramos } & Triclopir (50\%) & 10,15 Аа & 10,40 Аа & $10,98 \mathrm{Aa}$ & $10,58 \mathrm{Aa}$ & 9,28 Аа \\
\hline & Testemunha & 8,50 Aa & 9,58 Аа & $11,68 \mathrm{Aa}$ & 9,25 Аа & 10,70 Аа \\
\hline & $\mathrm{F}$ & $1,37^{(\mathrm{ns})}$ & $0,252 * *$ & $0,24^{(\mathrm{ns})}$ & $0,6^{\text {(ns) }}$ & $1,76^{(\mathrm{ns})}$ \\
\hline & DMS & & & 4,12 & & \\
\hline & CV (\%) & & & 20,62 & & \\
\hline & Tratamentos & & & Clones & & \\
\hline & & E.urograndis ${ }^{1}$ & E. urophylla & E. urograndis ${ }^{3}$ & E. urograndis ${ }^{2}$ & E. urocan \\
\hline & Fluro+triclo ${ }^{(25 \%)}$ & 21,85 & 28,50 & 26,35 & 26,58 & 24,69 \\
\hline & Fluro +triclo ${ }^{(50 \%)}$ & 21,45 & 23,25 & 36,24 & 32,27 & 31,47 \\
\hline MS(g) & Triclopir ${ }^{(25 \%)}$ & 24,40 & 18,83 & 28,96 & 33,10 & 27,21 \\
\hline \multirow[t]{9}{*}{ Folha } & Triclopir (50\%) & 22,50 & 20,80 & 48,05 & 37,65 & 40,66 \\
\hline & Testemunha & 25,45 & 29,13 & 32,48 & 25,68 & 20,65 \\
\hline & $\mathrm{F}$ & $0,252^{(\mathrm{ns})}$ & $1,78 * *$ & $1,47^{(\mathrm{ns})}$ & $0,67^{(\mathrm{ns})}$ & $1,08^{(\mathrm{ns})}$ \\
\hline & DMS & & & 13,64 & & \\
\hline & CV (\%) & & & 28,05 & & \\
\hline & Tratamentos & & & Clones & & \\
\hline & & E.urograndis ${ }^{1}$ & E. urophylla & E. urograndis ${ }^{3}$ & E. urograndis ${ }^{2}$ & E. urocan \\
\hline & Fluro+triclo ${ }^{(25 \%)}$ & $18,25 \quad \mathrm{ABa}$ & $16,83 \quad \mathrm{ABa}$ & $16,50 \mathrm{ABa}$ & $14,6 \quad \mathrm{Ba}$ & $20,50 \mathrm{Aa}$ \\
\hline & Fluro +triclo ${ }^{(50 \%)}$ & 16,18 & 18,65 Аа & $16,23 \mathrm{Aa}$ & 16,7 Аа & 18,48 Aab \\
\hline MS(g) & Triclopir (25\%) & 17,50 & $17,00 \quad \mathrm{Aa}$ & 13,90 Aa & 16,7 Аа & 15,98 Aab \\
\hline \multirow[t]{9}{*}{ Caule } & Triclopir (50\%) & 18,55 & 17,68 Aa & $14,33 \mathrm{Aa}$ & $14,0 \quad \mathrm{Aa}$ & 18,25 Aab \\
\hline & Testemunha & 13,75 & 15,23 Aa & 13,93 Aa & 11,8 Аа & $13,25 \mathrm{Ab}$ \\
\hline & $\mathrm{F}$ & $1,82^{(\mathrm{ns})}$ & $0,75^{(\mathrm{ns})}$ & $0,78^{(\mathrm{ns})}$ & $2,01^{(\mathrm{ns})}$ & $3,65^{(\mathrm{ns})}$ \\
\hline & DMS & & & 5,76 & & \\
\hline & CV (\%) & & & 17,9 & & \\
\hline & Tratamentos & & & Clones & & \\
\hline & & E.urograndis ${ }^{1}$ & E. urophylla & E. urograndis 3 & E. urograndis ${ }^{2}$ & E. urocan \\
\hline & Fluro+triclo $(25 \%)$ & 25,75 & 30,25 & 24,50 & 24,25 & 28,75 \\
\hline & Fluro +triclo ${ }^{(50 \%)}$ & 26,00 & 24,50 & 23,50 & 25,50 & 30,75 \\
\hline MS(g) & Triclopir (25\%) & 30,00 & 27,25 & 25,50 & 22,75 & 33,00 \\
\hline \multirow[t]{9}{*}{ Raiz } & Triclopir (50\%) & 33,25 & 32,50 & 30,50 & 31,75 & 27,75 \\
\hline & Testemunha & 30,75 & 26,00 & 24,00 & 26,25 & 26,75 \\
\hline & $\mathrm{F}$ & $1,034^{(\mathrm{ns})}$ & $1,04^{(\mathrm{ns})}$ & $0,8^{(\mathrm{ns})}$ & $1,16^{(\mathrm{ns})}$ & $0,62^{(\mathrm{ns})}$ \\
\hline & DMS & & & 12,62 & & \\
\hline & CV (\%) & & & 22,92 & & \\
\hline & Tratamentos & & & Clones & & \\
\hline & & E.urograndis ${ }^{1}$ & E. urophylla & E. urograndis ${ }^{3}$ & E. urograndis ${ }^{2}$ & E. urocan \\
\hline & Fluro+triclo $(25 \%)$ & 73,00 & 86,50 & 83,25 & 75,50 & 90,75 \\
\hline & Fluro +triclo ${ }^{(50 \%)}$ & 70,75 & 77,50 & 77,00 & 77,25 & 81,25 \\
\hline \multirow[t]{6}{*}{$\operatorname{MST}(\mathrm{g})$} & Triclopir $(25 \%)$ & 80,00 & 73,75 & 78,25 & 74,75 & 80,25 \\
\hline & Triclopir (50\%) & 84,50 & 81,50 & 78,50 & 73,75 & 75,75 \\
\hline & Testemunha & 78,75 & 80,25 & 82,00 & 72,50 & 71,50 \\
\hline & $\mathrm{F}$ & $0,499^{(\mathrm{ns})}$ & $0,366^{(\mathrm{ns})}$ & $0,117^{(\mathrm{ns})}$ & $0,052^{(\mathrm{ns})}$ & $0,845^{(\mathrm{ns})}$ \\
\hline & DMS & & & 31,18 & & \\
\hline & CV (\%) & & & 20 & & \\
\hline
\end{tabular}

Médias seguidas da mesma letra minúscula nas colunas e maiúsculas nas linhas não diferem estatisticamente pelo teste de Tukey ( $\leq 0$,05); $\left({ }^{*}\right)$ significativo a (pd”0,05) e $\left(^{\text {ns }}\right)$ não significativo. Fluro+triclo ${ }^{(25 \%)}$ : tratamento fluroxipir+triclopir a 25\% da dose recomendada; fluro+triclo ${ }^{(50 \%)}$ : tratamento fluroxipir+triclopir a 50\% da dose recomendada. E. urograndis ${ }^{1}=$ clone GG-100 (híbrido de E. urophylla $x$ grandis); E. urophylla = clone GG-157 (híbrido de E. urophylla); E. urograndis ${ }^{2}=$ clone VE-06 (híbrido de E. urophylla $x$ grandis); E. urograndis ${ }^{3}=$ clone HC (híbrido de E. urophylla x grandis); e E. urocan = clone VM-01 (híbrido de E. urophylla x camaldulensis). 
Esse comportamento pode ser explicado pelo fenômeno denominado "hormesis”, que supõe que em doses muito baixas os herbicidas poderiam estar estimulando o crescimento das plantas de eucalipto. Erlich introduziu o termo "hormesis" em 1943, para descrever o fenômeno no qual substâncias que são tóxicas em doses elevadas podem ser benéficas em doses baixas (CALABRESE, 2005).

O diâmetro do caule não apresentou diferenças significativas para nenhum dos tratamentos, nem para os clones testados. Em experimento simulando a deriva realizada por Tuffi Santos et al. (2006), foi verificado que a aplicação de subdose de triclopir (57,46 g ha ${ }^{-1}$ p.a) não afetou o diâmetro do caule das plantas de eucalipto.

Quanto ao acúmulo de matéria seca, verificou-se que, em ramos, o clone híbrido de E. urophylla $x$ grandis $^{1}$ em quase todos os tratamentos apresentou as menores médias, em comparação com os demais clones testados, e uma redução média na massa de $8,82 \%$ em relação à testemunha. Já em relação à massa seca de caules, os clones híbridos de E. urophylla x grandis $^{2}$ e híbrido de E. urophylla $x$ camaldulensis foram os menos afetados, com este último apresentando aumento de 54,7\% em incremento no tratamento fluroxipir + triclopir ${ }^{25}$, em comparação com a testemunha.

Tuffi Santos et al. (2006), trabalhando com Eucalyptus urophylla, observaram que os herbicidas glyphosate, triclopir e carfentrazone-ethyl, nas doses de 3, 6 e $12 \%$ das recomendadas, afetaram a altura e a massa de matéria seca da parte aérea, não sendo verificada diferença no diâmetro do caule.

\section{CONCLUSÕES}

Os herbicidas afetaram negativamente o crescimento dos clones de eucalipto até os 28 dias após a aplicação. O efeito da deriva é menor com triclopir e fluroxipir+triclopir, ambos a 25\% da dose.

\section{REFERÊNCIAS}

ABRAF, Anuário estatístico da ABRAF 2013. ano base 2012/ ABRAF. - Brasília, 2013. 130p.

ADORYAN, M. L et al. A. Eficácia e seletividade do herbicida isoxaflutole na cultura de Eucalyptus grandis. In: CONGRESSO BRASILEIRO DA CIÊNCIA DAS PLANTAS DANINHAS, 23., 2002, Gramado. Resumos.... Londrina: SBCPD/ Embrapa Clima Temperado, 2002. p. 572.
AGOSTINETTO, D. et al. Seletividade de genótipos de eucalipto a doses de herbicidas. Semina: Ciências Agrárias, v.31, n.3, p. 585-598, 2010.

AHRENS, W. E. Herbicide handbook Champaign: Weed Science Society of America, 1994. 352p.

CALABRESE, E. J. Historical blunders: how toxicology got the dose-response relationship half right. Cellular and Molecular Biology, v.51, p.643-654, 2005.

EMPRESA BRASILEIRA DE PESQUISA AGROPECUÁRIA - EMBRAPA. Sistema brasileiro de classificação de solos. 2. ed. Rio de Janeiro, Embrapa Solos, 2006. 306p.

FERREIRA, L. R. et al. Manejo integrado de plantas daninhas na cultura do eucalipto. - Viçosa, MG: Universidade Federal de Viçosa, 2010.

FERREIRA, F. A. et al. Mecanismos de ação de herbicidas. V Congresso Brasileiro de Algodão. Disponível em: http://www. cnpa. embrapa.br, 2005.

FRANS, R. E. Measuring plant responses. In: WILKINSON, R. E. (Ed.). Research methods in weed science.[S.l.]: Southern Weed Science Society, 1972. p.28-41.

GROSSMANN, K. Mode of action of auxinic herbicides: a new ending to a long, drawn out story. Trends Plant Science, v.5, n.12, p.506-508, 2000.

GROSSMANN, K.; HANSEN, H. Ethylenetriggered abscisic acid: A principle in plant growth regulation? Physiologia Plantarum, v. 113, n. 1, p. 9-14, 2001.

MACHADO, A. F. et al. Eficiência fotossintética e uso da água em plantas de eucalipto pulverizadas com glyphosate. Planta Daninha, v. 28, n. 2, p. 319-327, 2010.

NUNES, S. G. Controle de plantas invasoras em pastagens cultivadas nos Cerrados.Campo Grande: Embrapa Gado de Corte, 2001.

PEEL, M.C.et al. Update world map of the Köppen-Geiger climate classification. Hydrology Hydrology and Earth Systems Sciences, v. 11, p. 1633-1644. 2007. 
RODRIGUES, B. N.; ALMEIDA, F. S. Guia de herbicidas. 3. ed. Londrina: IAPAR, 2005591 p.

SILVA, W. et al. Tolerância de Eucalyptus spp a diferentes herbicidas. Revista Árvore, v. 18, n. 3, p. 287-300, 1994.

TAIZ L, ZEIGER E. Plant physiology. Sunderland: Sinauer Associates, 1998.

TAMAS, I.A. Hormonal regulation of apical dominance. In: DAVIES, P.J. (Ed) Plant hormones, physiology, biochemistry and molecular biology. Dordrecht: Kluwer Academic Publishers, 1995.p.572-597.

TIBURCIO, R. A. S. et al. Crescimento de mudas de clones de eucalipto submetidos à deriva simulada de diferentes herbicidas. Revista Árvore, v.36, n.1, p.65-73, 2012.
TUFFI SANTOS, L. D. et al. Crescimento e morfoanatomia foliar de eucalipto sob efeito de deriva do glyphosate. Planta Daninha, v. 23, n.1, p.133-142, 2005.

TUFFI SANTOS, L. D. et al. Intoxicação de eucalipto submetido à deriva simulada de diferentes herbicidas. Planta Daninha, Viçosa-MG, v. 24, n. 3, p. 521-526, 2006.

TUFFI SANTOS, L. D. et al. Morphological responses of different eucalypt clones submitted to glyphosate drift. Environmental and Experimental Botany, v.59, n.1, p.11-20, 2007.

TAKAHASHI, E. N. et al. Consequências da deriva do clomazone e sulfentrazone em clones de E. grandis x E. urophylla. Revista Árvore, v.33, n.4, p.675-683, 2009. 
